\title{
KEY FACTS ON COMMUNITY FOUNDATIONS
}

\section{September 2007}

\section{OUTLOOK FOR COMMUNITY FOUNDATION GIVING}

Community foundations account for 1 percent of all U.S. grantmaking foundations but almost 9 percent of giving. In 2006, their estimated giving rose 13.2 percent to a record $\$ 3.6$ billion-surpassing independent and corporate foundations but falling below the estimated increase for operating foundations. Contributing to the faster growth in community foundation giving has been strong asset growth, new gifts and bequests from donors, and exceptional disbursements from donor-advised funds. Community foundations have benefited from three consecutive years of double-digit growth in assets, while the assets of independent and corporate foundations have risen annually at single-digit rates. Relative to other types of foundations, community foundations benefit from having a broad pool of individual donors who can respond quickly to economic upturns and also balance out those that have reduced giving. Donor-advised funds maintained by community foundations may also be seen as a less costly and time-consuming alternative to setting up an independent foundation. The funds can also provide the means for donors with multiple philanthropic vehicles and giving priorities to more easily segment their giving.

1. For more details see S. Lawrence, A. Austin, and R. Mukai, Foundation Growth and Giving Estimates: Current Outlook, The Foundation Center, New York, NY, 2007.
Looking ahead, three-fifths (60 percent) of community foundations responding to the Foundation Center's annual forecasting survey expected to increase their giving in $2007 .{ }^{1}$ Most of these funders anticipated giving increases in the 1 to 5 percent and 5 to 10 percent ranges. Yet this potentially positive finding was tempered by the 29 percent of community foundation respondents that expected to reduce their giving in 2007.

Three out of five surveyed community foundations expected to increase giving in 2007; nearly three-tenths anticipated reductions

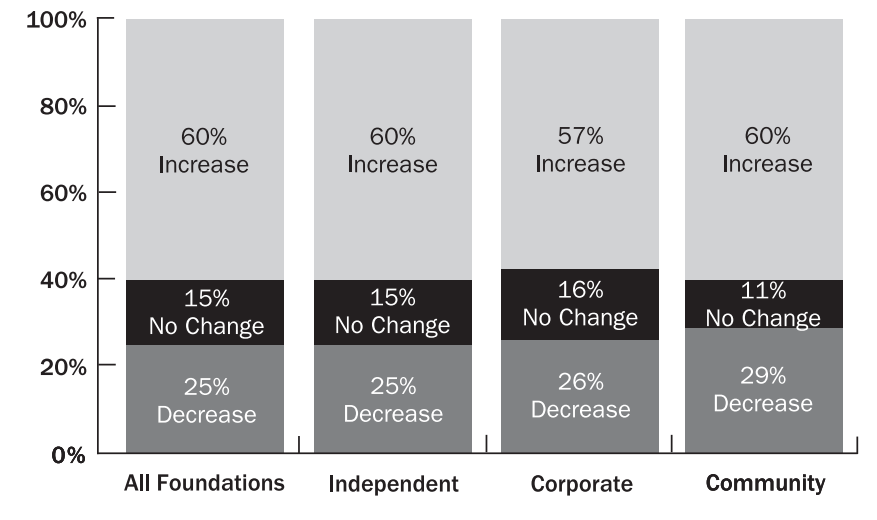

Note: A total of 832 foundations responded to this question.

Inflation-adjusted community foundation giving has increased nearly fivefold since 1990

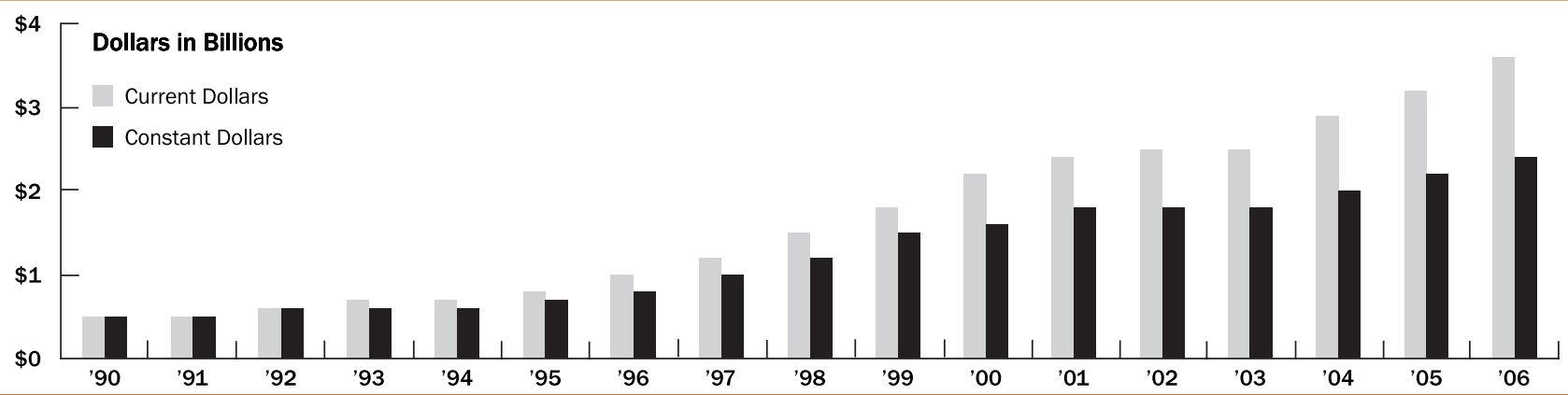

Note: Figures estimated for 2006 


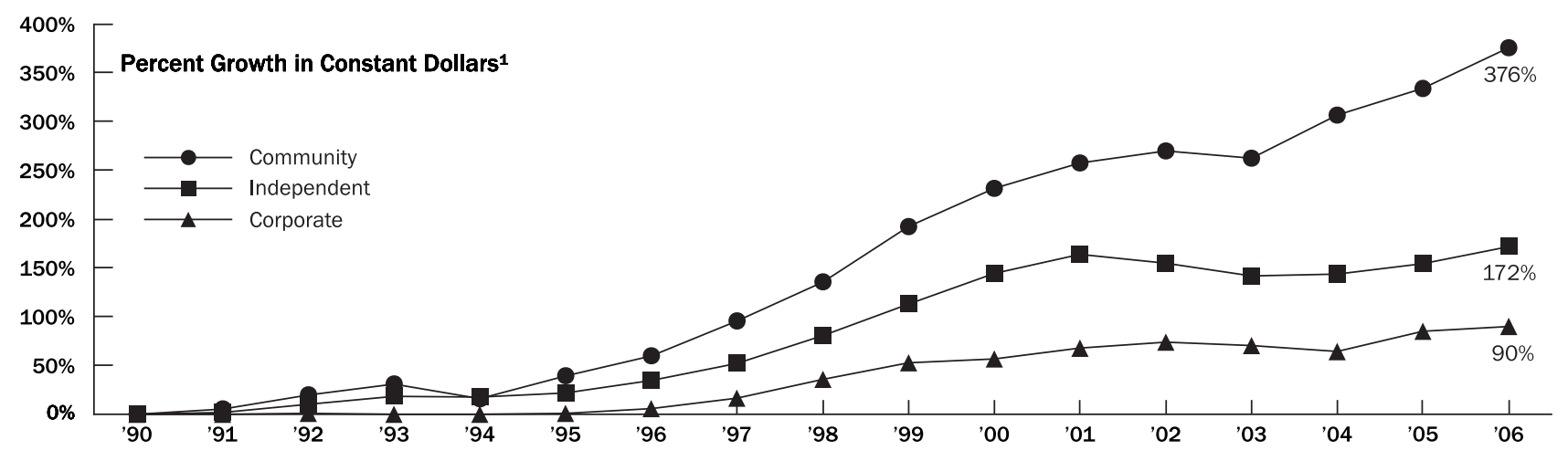

Note: Figures estimated for 2006

${ }^{1}$ Percent change in constant 1990 dollars based on annual average Consumer Price Index, all urban consumers (Source: U.S. Department of Labor, Bureau of Labor Statistics, as of February 2007).

Since 1990, community foundations have increased their overall share of foundation giving

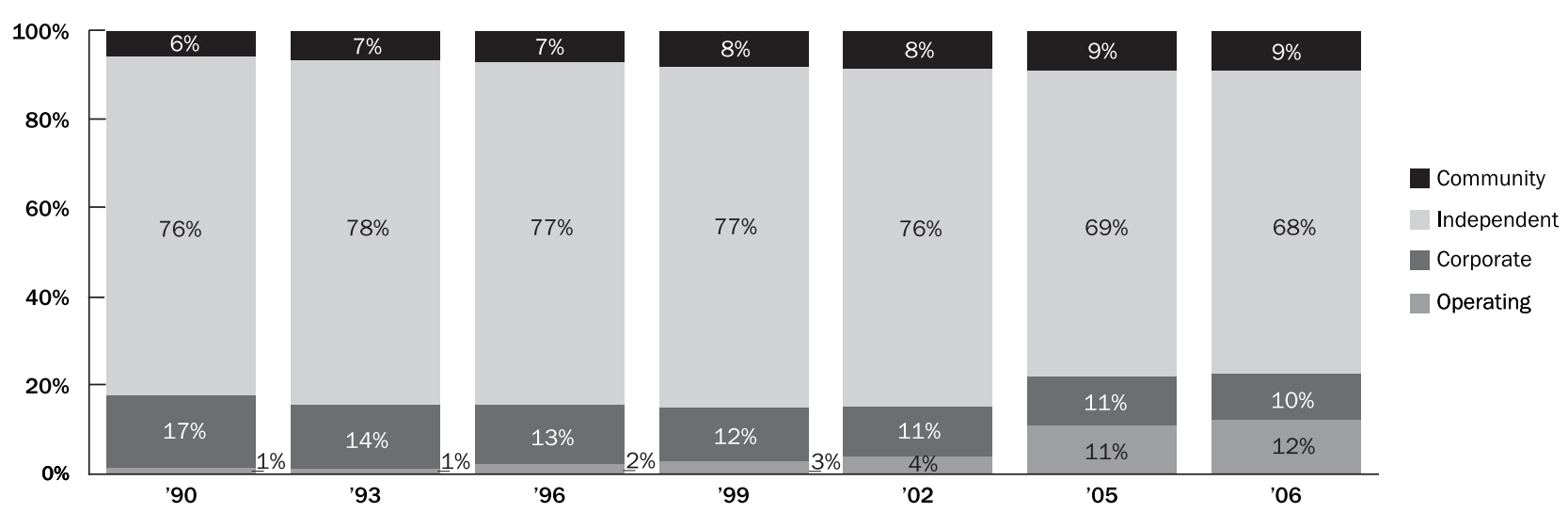

Note: Based on total giving by 71,095 grantmaking private and community foundations. Due to rounding, percentages may not total 100 .

\section{SUMMARY STATISTICS FOR COMMUNITY FOUNDATIONS}

\section{Change in Community Foundations, 1990 to 2005}

\begin{tabular}{lrr|rr}
\hline & & & \multicolumn{2}{c}{$\%$ Change } \\
& 1990 & $\mathbf{2 0 0 5}$ & Current & Constant $^{1}$ \\
\hline No. of Foundations & 328 & 707 & 115.5 & \\
Total Giving & $\$ 495,886$ & $\$ 3,217,048$ & 548.7 & 334.2 \\
Total Assets & $\$ 6,622,440$ & $\$ 44,583,970$ & 573.2 & 350.5 \\
Gifts Received & $\$ 609,391$ & $\$ 5,586,604$ & 816.8 & 513.5 \\
\hline
\end{tabular}

Note: Dollars in thousands.

${ }^{1}$ Percent change in constant 1990 dollars based on annual average Consumer Price Index, all urban consumers

(Source: U.S. Department of Labor, Bureau of Labor Statistics, as of February 2007).
Community foundation giving represented close to one-tenth of total foundation giving in 2005

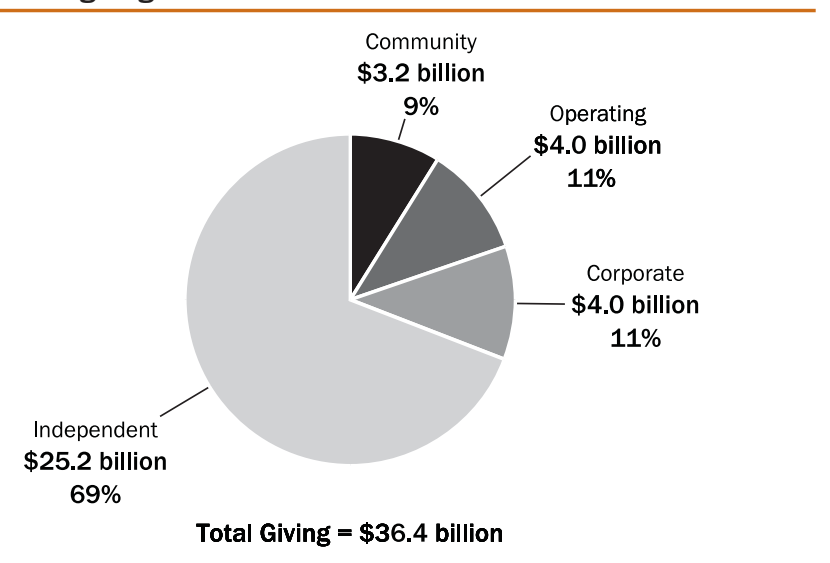

Note: Based on total giving by 71,095 grantmaking private and community foundations. 
Half of community foundations reported less than $\$ 10$ million in assets in 2005

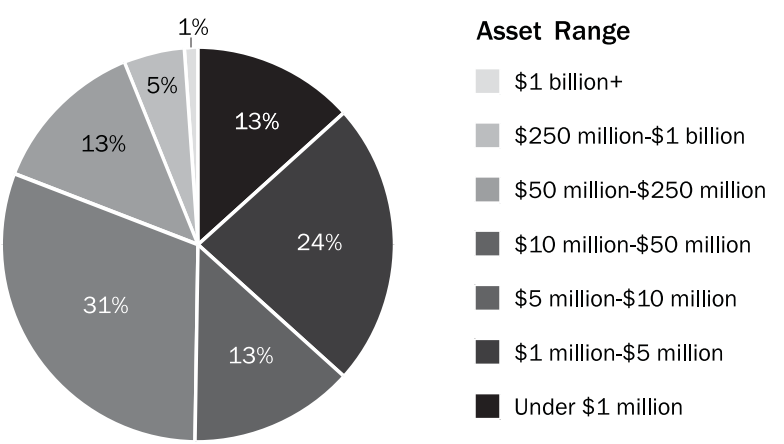

Percent of Number of Foundations

Note: Based on 707 grantmaking community foundations.

The Midwest accounted for close to half of community foundations in 2005

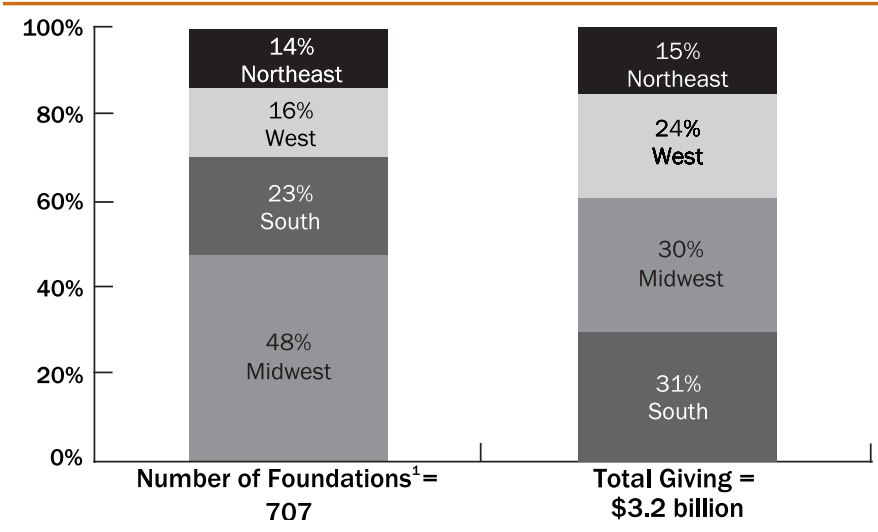

Note: Giving includes grants, scholarships, and employee matching gifts; excludes set-asides, loans, PRIs, and program expenses.

${ }^{1}$ Number of community foundations includes one foundation located in Puerto Rico and one in the Virgin Islands.
More than three-fifths of community foundations reported less than \$1 million in giving in 2005

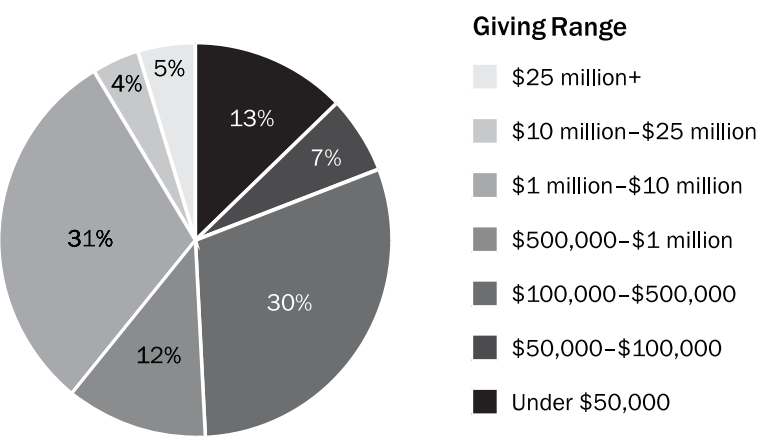

Percent of Number of Foundations

Note: Based on total giving by 707 grantmaking community foundations.

Community Foundations by State, 2005

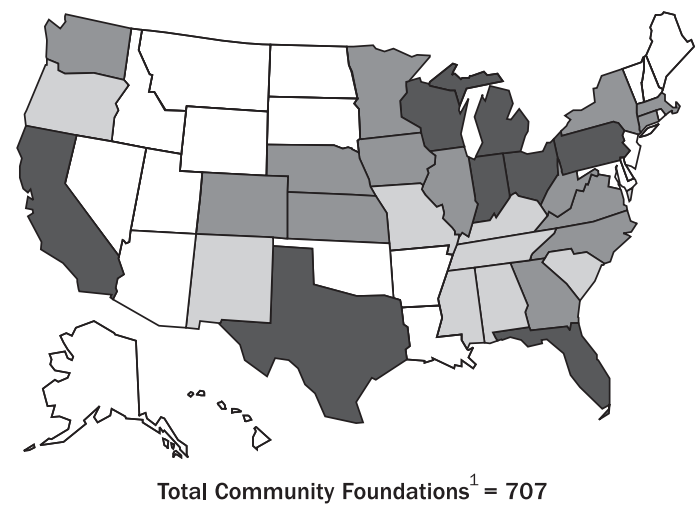

20+ $\square$ 10-under $20 \quad \square$ 5-under $10 \quad \square$ Under 5

${ }^{1}$ Number of community foundations includes one foundation located in Puerto Rico and one in the Virgin Islands.

Top 25 Community Foundations by Total Giving, 2005

\begin{tabular}{|c|c|c|c|c|c|}
\hline Foundation & State & Total Giving ${ }^{1}$ & Assets & Gifts Received & Fiscal Date \\
\hline 1. Greater Kansas City Community Foundation & $\mathrm{MO}$ & $\$ 140,702,000$ & $\$ 1,013,035,000$ & $\$ 157,300,000$ & $12 / 31 / 2005$ \\
\hline 2. New York Community Trust & NY & $136,970,963$ & $1,897,604,374$ & $126,518,677$ & $12 / 31 / 2005$ \\
\hline 3. Greater Houston Community Foundation & TX & $109,144,475$ & $199,126,686$ & $152,970,092$ & $12 / 31 / 2005$ \\
\hline 4. Peninsula Community Foundation ${ }^{2}$ & $\mathrm{CA}$ & $92,331,777$ & $614,336,446$ & $63,219,720$ & $12 / 31 / 2005$ \\
\hline 5. California Community Foundation & $\mathrm{CA}$ & $91,367,805$ & $1,152,601,808$ & $466,617,193$ & $6 / 30 / 2006$ \\
\hline $\begin{array}{l}\text { 6. Community Foundation for the National } \\
\text { Capital Region }\end{array}$ & DC & $91,235,382$ & $346,982,198$ & $80,688,350$ & $3 / 31 / 2006$ \\
\hline 7. Community Foundation for Greater Atlanta & GA & $89,391,237$ & $638,817,268$ & $105,617,249$ & $6 / 30 / 2006$ \\
\hline 8. Chicago Community Trust & IL & $75,988,536$ & $1,503,994,247$ & $81,325,064$ & $9 / 30 / 2005$ \\
\hline 9. Community Foundation Silicon Valley ${ }^{2}$ & $\mathrm{CA}$ & $75,366,593$ & $760,821,244$ & $140,184,428$ & $6 / 30 / 2005$ \\
\hline 10. San Francisco Foundation & $\mathrm{CA}$ & $68,100,000$ & $883,443,000$ & $70,888,000$ & $6 / 30 / 2006$ \\
\hline 11. Cleveland Foundation & $\mathrm{OH}$ & $66,421,855$ & $1,716,136,165$ & $29,029,674$ & $12 / 31 / 2005$ \\
\hline 12. Columbus Foundation and Affiliated Organizations & $\mathrm{OH}$ & $65,626,215$ & $850,089,853$ & $67,974,224$ & $12 / 31 / 2005$ \\
\hline 13. Boston Foundation & MA & $63,914,314$ & $769,807,869$ & $73,560,736$ & $6 / 30 / 2006$ \\
\hline 14. Communities Foundation of Texas & TX & $59,931,000$ & $699,873,000$ & $73,397,000$ & $6 / 30 / 2006$ \\
\hline 15. Foundation for The Carolinas & NC & $59,551,103$ & $424,272,918$ & $64,829,466$ & $12 / 31 / 2005$ \\
\hline 16. Omaha Community Foundation & NE & $53,598,735$ & $393,005,266$ & $53,617,510$ & $12 / 31 / 2005$ \\
\hline 17. Marin Community Foundation & $\mathrm{CA}$ & $51,649,386$ & $1,125,930,427$ & $40,303,555$ & $6 / 30 / 2006$ \\
\hline 18. Baltimore Community Foundation & MD & $46,272,563$ & $166,036,468$ & $19,475,619$ & $12 / 31 / 2005$ \\
\hline 19. Seattle Foundation & WA & $45,948,620$ & $473,444,919$ & $60,596,389$ & $12 / 31 / 2005$ \\
\hline 20. San Diego Foundation & $\mathrm{CA}$ & $43,516,000$ & $484,163,000$ & $37,005,000$ & $6 / 30 / 2006$ \\
\hline 21. Oregon Community Foundation & OR & $40,478,757$ & $850,034,138$ & $74,255,623$ & $12 / 31 / 2005$ \\
\hline 22. Minneapolis Foundation & MN & $37,154,937$ & $654,649,964$ & $21,777,780$ & $3 / 31 / 2006$ \\
\hline 23. Community Foundation of Middle Tennessee & TN & $35,063,130$ & $368,437,097$ & $44,710,301$ & $12 / 31 / 2005$ \\
\hline 24. Saint Paul Foundation & MN & $34,675,706$ & $617,910,511$ & $24,925,219$ & $12 / 31 / 2005$ \\
\hline 25. Dayton Foundation & $\mathrm{OH}$ & $33,858,562$ & $298,963,813$ & $61,275,205$ & $6 / 30 / 2006$ \\
\hline
\end{tabular}

${ }^{1}$ Includes grants, scholarships, and employee matching gifts; excludes set-asides, loans, PRIs, and program expenses.

${ }^{2}$ In 2006, the Peninsula Community Foundation and the Community Foundation Silicon Valley merged to become the Silicon Valley Community Foundation. 
Education and human services were the top priorities of community foundations in 2005

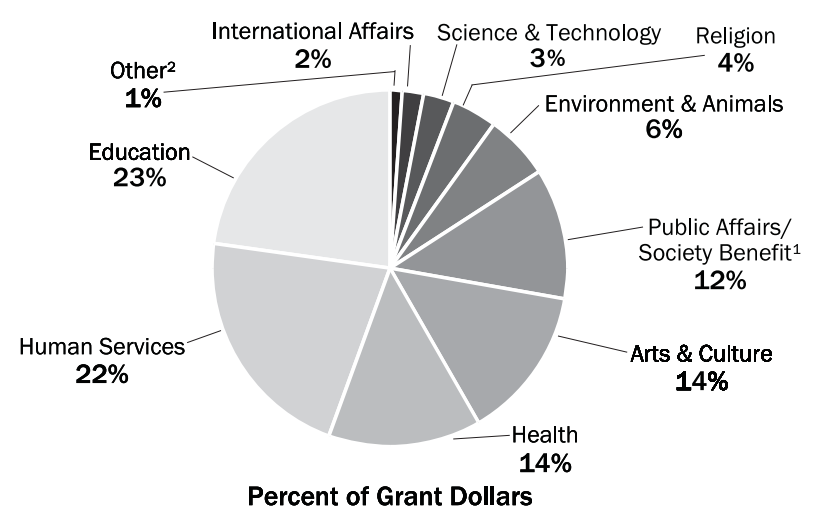

Note: Based on a sample of 88 larger community foundations.

${ }^{1}$ Includes Civil Rights and Social Action, Community Improvement and Development, Philanthropy and Voluntarism, and Public Affairs.

Includes 0.5 percent of community foundation grant dollars awarded for the social sciences.

Community foundations provided larger shares of their funding for human services, the arts, and religion than other foundations in 2005

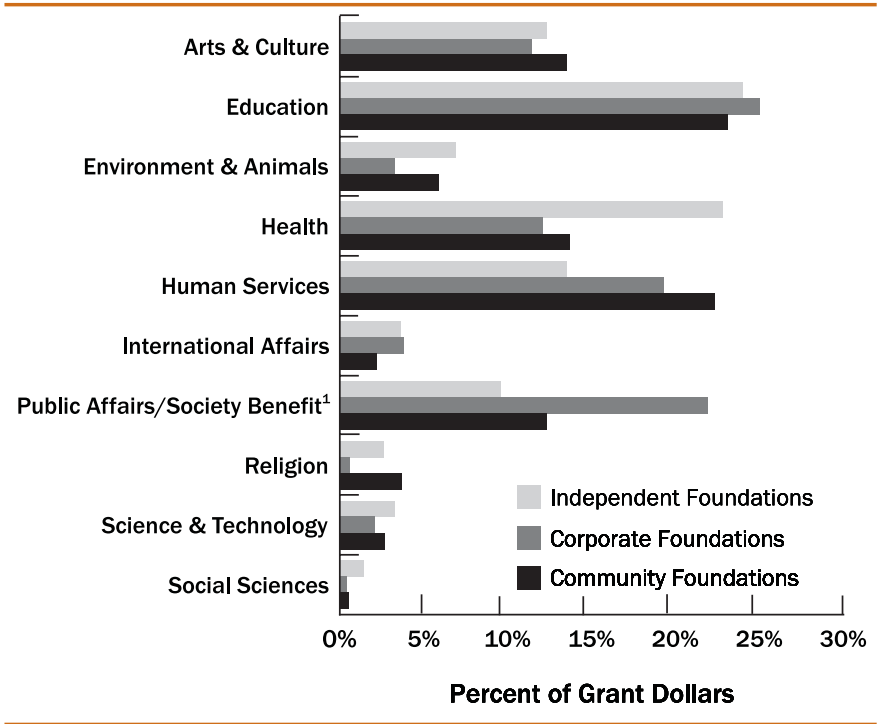

Note: Based on a sample of 1,154 larger foundations, including 88 community foundations.

${ }^{1}$ Includes Civil Rights and Social Action, Community Improvement and Development, Philanthropy and

Voluntarism, and Public Affairs.

Community foundations allocated a larger share of their grant dollars for operating support than did foundations overall in $\mathbf{2 0 0 5}$

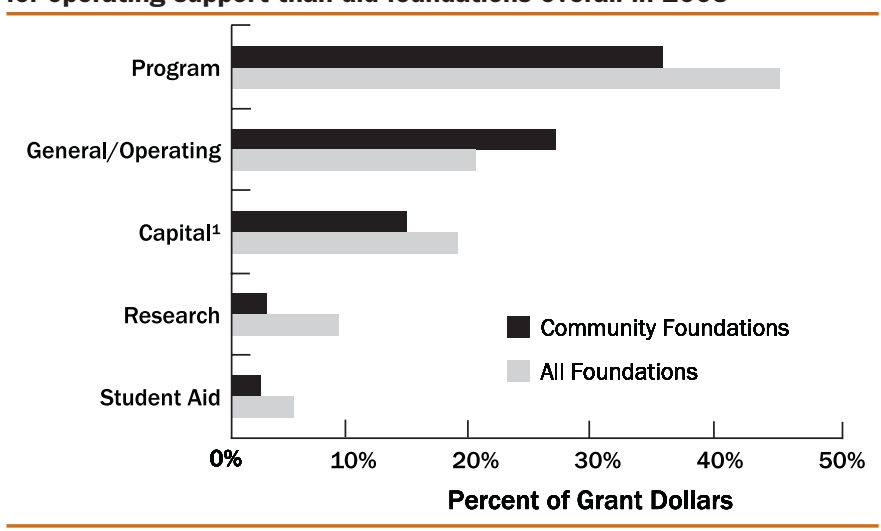

Note: Based on a sample of 1,154 larger foundations, including 88 community foundations. Approximately 26 percent of community foundation grant dollars could not be identified by type of support.

${ }^{1}$ Includes endowment funds.

\section{COMMUNITY FOUNDATION GIVING PATTERNS, 2005}

The larger community foundations included in the Foundation Center's 2005 grants sample ${ }^{2}$ were more likely than independent and corporate foundations to provide funding for human services, the arts, and religion. Much of the larger share of support for human services reflected giving for multipurpose programs, which include a broad range of services to individuals and families. By target population group, community foundation giving primarily benefited the economically disadvantaged and children and youth-consistent with independent and corporate foundations. Nonetheless, community foundations gave proportionately more than foundations overall for people with disabilities, the aging, crime or abuse victims, and substance abusers.

\section{The Foundation Center's 2005 grants sample database includes all of the grants of $\$ 10,000$ or more awarded by 1,154 of the largest U.S. foundations, including 88 community foundations. The overall sample accounted for roughly half of grant dollars awarded by the nation's more than 71,000 grantmaking foundations.}

Community foundations prioritized giving for children and youth and the economically disadvantaged in 2005

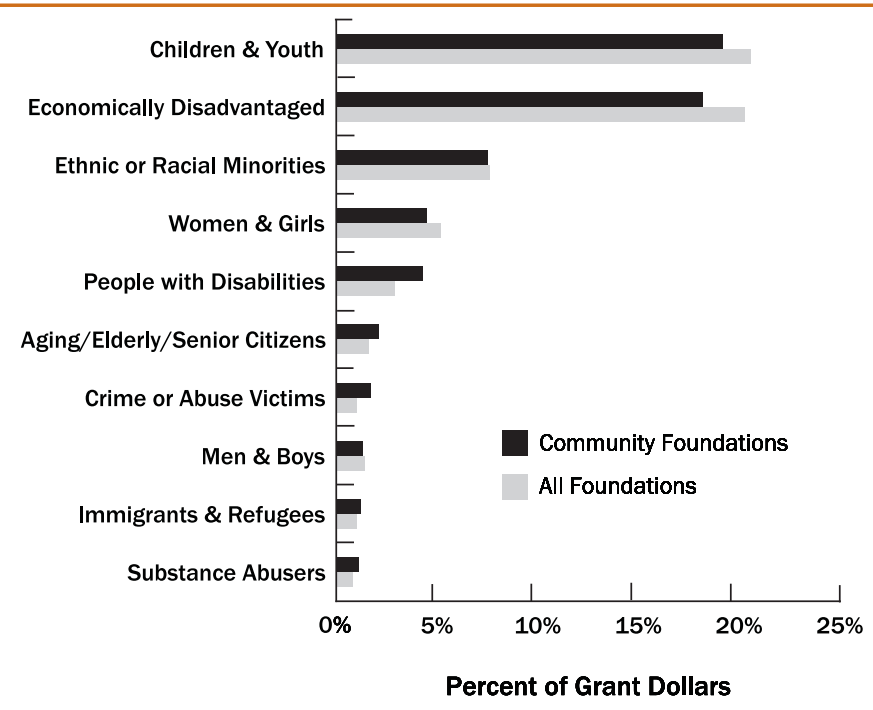

Note: Based on a sample of 1,154 larger foundations, including 88 community foundations. Chart includes selected beneficiary groups representing at least 1 percent of community foundation grant dollars. Figures selected beneficiary groups representing at least 1 percent of community foundation grant dollars. Figures (eprest groups. In addition, grants may benefit multiple population groups, e.g., a grant for homeless children, and would therefore be counted more than once.

Source for all data: The Foundation Center

For more information, contact Reina Mukai, research associate at the Foundation Center, at (212) 807-2485, or via e-mail at rkm@foundationcenter.org. “Key Facts on Community Foundations" is available at foundationcenter.org. 